\title{
Optimizing the cutting of tension wood in Rubberwood: an economic and quality perspective
}

\begin{abstract}
A study was carried out to measure the cutting force and the resultant machined surface quality for tension wood and normal wood of Rubberwood using a single saw tooth experimental set-up. Three different saw tooth geometries were used in the experiment, to establish the optimum saw tooth design for the sawing of tension wood. The results showed that the specific principal cutting force was lower for tension wood compared to normal wood, due to the less lignified cell walls of the tension wood. It appears that the lignin component in the cell wall provides the stiffness to the cell wall, which was lacking in the cell walls of tension wood, hence reducing the cutting forces significantly. Nevertheless, the overall power consumption during the machining of tension wood was markedly higher due to the presence of fuzzy grains on the machined surface of tension wood, which increased the frictional force acting on the cutting edges during the machining process. Further, it was found that saw tooth design No. 2 produced the optimal result, both from the economic and quality perspectives for the sawing of tension wood. Therefore, in order to optimize the sawing of tension wood, saw tooth with the highest rake and clearance angles is recommended as it required the least cutting force, while producing the best surface quality. This study has far reaching industrial implications on the sawing and machining of Rubberwood in the South East Asian region.
\end{abstract}

Keyword: Abnormal wood; Sawing; Machined surface; Fuzzy grain 